\title{
Asian migrant women's identity negotiation as language learners: Significant events towards imagined identities
}

\section{Jinah Lee}

\begin{abstract}
Social identity issues come to the fore when people migrate from one place to another. Study of identity issues has been a central theme in understanding migrants. However, ambiguous and complex identity negotiation processes have been underexplored. Recently, demographic changes in Aotearoa New Zealand, due to the increase in the population of Asian migrants, concern many, because there is little known about the population in relation to the migrants' experiences in identity changes. This thesis will therefore attempt to unfold the complexity of identity negotiation processes in the study of Asian migrants in Aotearoa New Zealand, in particular, mothers. This research can provide a further understanding of the population and can contribute to the academic field of identity theories.
\end{abstract}

Asian migrant women as language learners struggle to settle in Aotearoa New Zealand. They hope to belong to the society through identity negotiation. The process of negotiation is individually different and dynamic. However, socially informed identity theories guided by Wenger's (1999) Communities of Practice framework provide a starting point to explore the dynamics of these processes. This research not only seeks to examine the complexity of these negotiations but also to develop a structure which can explain such complexity.

The research design was underpinned by theoretical concepts of social constructionism and narrative inquiry. To capture the dynamic identity negotiation processes, I collected narratives of significant events. Six Asian migrant women living in Hamilton, Aotearoa New Zealand, participated in the research. They engaged in prompted recounts and eight in-depth individual interviews, which consisted of one initial, six post-recount and one reflective interview, during a twelve-month period. The iterative interview process also included the researcher's responses to the participants' shared stories, and reflective journal writings after each interview session.

The findings show that identities of the participants are not static and are related to the complex relation of imagined identities and past experiences, in the context of local and global environments. The dynamism of the participants' identities is also linked to the changing nature of their recounts in relation to the perceived level of significance. These ongoing shifts are shown in interview contexts. During the interviews, the participants often add statements to increase their self-value while they narrate stories indicating a weak sense of belonging. The statements are performed as strategies (Marginson, 2014), and the strategies are diversity and hybridity. Also, the dyadic relationships that developed between the participants and the researcher during the interviews, which were outcomes of the methodological frame, proved to have played a role in increasing the participants' self-value and the possibilities of positive identities. 
The discussion of the findings presents close connections between a sense of belonging and sense of self-value in relation to identities. The participants' identity negotiation processes took place in relational contexts. The contexts reflect important aspects of dyadic relationships in the negotiation processes. The results provide implications for social identity theories, narrative research, and pedagogies of EAL teaching and learning. 